\title{
Panukalang kurikulum sa Filipino sa senior high school
}

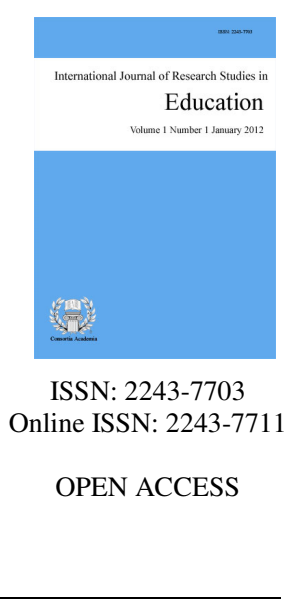

\section{Abstract}

Ang pag-aaral na ito ay isang pagtaka upang bigyang pansin ang mas mataas na antas ng pag-aaral ng wika at panitikang Filipino sa senior high school sa Pilipinas. Sa kabila ng pagkakaroon ng mga asignaturang Filipino sa senior high school mula sa kurikulum ng Kagawaran ng Edukasyon, nagpapanukala ang mga mananaliksik ng mga bagong asignaturang mas lapit sa danas ng lipunan at nakasandig sa global at lokal na konteksto. Gayundin, ang pagtalakay sa lokal na panitikan ay naglalayong gawing matatag ang kultural na ugat ng mga mag-aaral. Apat na asignatura ang ipinapanukala, 1) Wikang Filipino sa Panahon ng Globalisasyon, 2) Pagsasaling-wika sa Iba't ibang Larangan, 3) Pagpapahalaga sa Rehiyunal at Pambansang Panitikan, at 4) Malikhaing Pagsulat sa Kulturang Pilipino. Ang mga panukalang asignaturang ito ay nagnanais na malinang ang analitiko, kritikal, kolaboratibo, komunikatibo, malikhaing pag-iisip ng mga mag-aaral.

Keywords: kurikulum sa Filipino; senior high school; panitikan; wika; globalisasyon 


\section{Panukalang kurikulum sa Filipino sa senior high school}

\section{Panimula}

Isa sa mga layunin sa pagtuturo ng wika ay ang paghubog sa literasi ng mga mag-aaral. Sa batayang antas ng edukasyon, nakapokus ang pagtuturo sa paglinang sa kasanayan sa pakikinig, pagsasalita, pagbasa, pagsulat at panonood na kilala sa tawag na limang makrong kasanayan. Sa pagtaas ng antas ng pag-aaral ay tumataas din ang mga kasanayang nilalayong malinang sa mga mag-aaral.

Ayon sa kurikulum ng Kagawaran ng Edukasyon, itinuturo ang Filipino bilang asignatura mula baiting isa (1) hanggang baitang sampu (10) upang malinang ang kakayahang komunikatibo, replektibo at mapanuring pag-iisip, at pagpapahalagang pamanitikan ng mga mag-aaral. Samu't sari ang mga paksang kinapapalooban nito at mga gawaing patungo sa pagtamo sa mga layuning nabanggit.

Sa pagsusuring isinagawa, nabuo ang kongklusyon na walang continuity ang mga konsepto, kasanayan mula sa junior high school patungong senior high school. Ito ay nakikitang suliranin dahil maaaring magkulang sa lalim (depth) ang pagpapahalaga at paglinang sa mga konsepto at kasanayan ang mga mag-aaral. Dahil dito, ipinapanukala na bigyang pagpapalalim ang pag-unawa at pagpapahalaga ng mga mag-aaral sa paggamit ng wikang Filipino sa gitna ng kasalukuyang lagay ng mundo at globalisasyon. Gayundin, upang bigyang diin ang kalahagahan ng panitikan sa pambansang pagkakaunawaan, nilalaman din ng kurikulum na ito ang muling pagtuturo ng panitikang rehiyonal at pambansa sa mas mataas na antas ng pagsusuri at pananaw.

Ang lahat ng ito ay nakasandig sa pangkalahatang layunin ng pagpapatupad ng K-12 na programa sa bansa partikular sa pagdaragdag ng senior high school o dalawa pang taon para sa batayang antas ng edukasyon. Nilalayon nito na maihanda ang bawat mag-aaral sa kahingian ng mundo. Dapat matamo ng bawat mag-aaral ang kaalaman, kasanayan at pagpapahalagang magagamit nila hindi lamang sa loob ng bansa ngunit maging sa iba pang panig ng mundo.

Dahil ang senior high school ang dulo ng batayang antas ng edukasyon sa Pilipinas, nararapat na magkaroon ang bawat mag-aaral ng kinakailangan kaalaman, kasanayan at pagpapahalagang magagamit sa anumang landas na kanilang tatahakin, maging ito man ay trabaho o lalong mataas na edukasyon.

Ang pinakabagong pagbabago sa sistema ng edukasyon ng Pilipinas ay ang pagpapatupad ng Enhanced Basic Education Act of 2013. Ilan sa mga nilalaman nito ay ang pagtuturo sa una hanggang ikatlong baitang batay sa Mother-Tongue Based Multilingual Education (MTBMLE), pagsang-ayon ng kurikulum sa spiral progression approach, pagdaragdag ng dalawang taon sa senior high school, at pagpapalit ng nilalaman ng ilang asignatura. Sa ilang taon makalipas ang implementasyon nito, maramig pag-aaral ang naisagawa. Marami ang nagsasabing maganda ang nagiging resulta nito. Ngunit, marami rin ang napatunayang kakulangan ng kurikulum.

Mula pa noong 1940 sa panahon ni dating Pangulo Manuel L. Quezon ay itinuturo na sa pampubliko at pribadng paaralan ang wika batay sa Pangkautusang Ehekutibo bilang 263. Ito ay kinilala noong wikang Tagalog, ang pambansang wika ng Pilipinas. Ayon sa mga eksperto noong panahon iyon, napadali ng pagtuturo gamit ang wikang Tagalog dahil mas madali itong maunawaan ng mga Pilipino (Espiritu, n. d.).

Ayon naman sa Saligang Batas ng 1987, Artikulo XIV, Seksyon 7, wikang Filipino ang opisyal na wika ng Pilipinas at gagamitin ito sa komunikasyon at pagtuturo. Ito ay patibay na may mahalagang gampanin ang wikang Filipino sa ating lipunan. Ito rin ang nasisilbing matibay na sandigan ng pagtuturo ng Filipino sa iba;t ibang antas ng edukasyon. Gayundin, ang paglinang sa kasanayang komunikatbo sa Filipino ng mga mag-aaral ay kinakalingan upang maisakatuparan ang probisyong ito ng batas. 
Ang mga probisyong ito ng batas sa bansa ang batayan sa pagpili ng mga asignaturang ipinanukalang ipatutupad sa senior high school. Ang mga ito para sa mas epektibo at episyenteng pagtuturo at pagkatututo, at pagpapanitiling mahalaga at buhay ng wika at kulturang Pilipino.

Sa aspeto naman ng pagsasaling-wika, binanggit ni Batnag (n. d.), ang pagsasalin ay naging paraan na upang maipahayag ang pagiging makabayan at liberal ng mga Pilipino. Nagsimula bilang gawaing panrelihyon, nagpabago ang pananaw ng mga Pilipino ukol sa pagsasalin. Sa panahon nga ng mga Amerikano, pinasok nan $g$ pagsasalin sa bansa ang domeyn ng edukasyon. Isinasalin na rito ang iba't ibang kagamitang pampagtuturo. Gayundin, ang layunin ng pagsasaling-wika bilang asignatura ay ang maisalin sa wikang Filipino ang iba;t ibang teksto ay materyales mula sa ibang wika upang mas madaling maunawaan ng mga Pilipino.

Sa artikulong inilathala ng The Varsitarian ng Unibersidad ng Sto. Tomas, inilahad na hindi raw sapat ang mga kasanayang itinuturo sa senior high school (Ocampo, 2016). Ipinaliwanag na kinakailangan pa ang maraming pananaliksik upang maitaguyod ang pagiging intelektwalisado ng wikang Filipino. Samakatuwid, kailangan nga ang maraming gawain sa pagsulat.

Isa pa sa mga pinagbatayang pag-aaral sa pagpapanukala sa asignaturang Filipino ay ang konsepto ni Cummins (1984) ukol sa Cognitive-Academic Language Proficiency (CALP). Ito ay nagpapaliwanag sa paggamit ng wika ng mga mag-aaral sa mas mataas na antas partikular sa mga kognitibo at akademikong gawain. Dito nakapokus ang mga asignaturang ipinanukala sa papel na ito. Nilalayon nitong magamit ang wikang Filipino sa akademikong larangan na nangangailangan ng mga kasanayang kognitibo.



Figure 1. Balangkas Konseptwal

Ipinapakita ng balangkas konseptwal na ito ang batayang pilosopiya ng mga asignatura at layunin ng mga ito. Gayundin, makikita sa gitna ang mag-aaral na kalalabasan ng kurikulum na ito. Nakaangkla sa pilosopiyang pragmatism ang mga asignaturang Wikang Filipino sa Panahon ng Globalisasyon at Pagsasaling-wika sa Iba't ibang Larangan sapagkat nakikita na ito ang mga kosnepto at kasanayang kinakailangan ng mga mag-aaral sa kanilang tatahakin propesyon o larangan sa hinaharap. Existentialism at perennialism naman ang pilosopiyang kinasasandigan ng mga asignaturang Malikhaing Pagsulat sa Kulturang Pilipino at Pagpapahalaga sa Rehiyonal at Pambansang Panitikan. Dito binibigyang pagkakataon ang mga mag-aaral na pahalagahan ang yaman ng bayan at bansang kanilang kinabibilangan at makapagpahayag sa paraang malikhain. Ang mga asignaturang ito ang magbibigay ng mga kinakailangan kaalaman, kasanayan at pagapahalaga sa mga mag-aaral makapag-isip sa aspetong global o pandaigdigan at kumilos sa paraan at may pagpapahalagang lokal. 
Nilalayon ng panukalang kurikulum sa Filipino para sa senior high school na ito ang mga sumusunod:

$>\quad$ magkaroon ng malinaw na kosepto ng wikang Filipino;

> makabasa ng mga artikulo at iba pang sulatin ukol sa gampanin ng wikang Filipino sa kasaysayan at kasalukuyang panahon;

$>$ makasulat gamit ang wikang Filipino ukol sa iba't ibang isyung panlipunan;

$>$ makapagsalin ng iba't ibang teksto sa iba't ibang larangan;

$>$ makilala, masuri at mapahalagahan ang iba’t ibang rehiyonal at pambansang panitikan;

$>$ makapagsulat ng iba't ibang akdang pampanitikan

$>\quad$ magkaroon ng mag-aaral na may mataas na pagpapahalaga sa wika at panitikang Filipino.

\section{Metodolohiya}

Ang papel na ito ay gumamit ng mga literatura upang mabuo ang mga panukalang asignatura sa Filipino sa SHS. Nakasandig ang nilalaman nito sa mga literature ukol sa pagdevelop at pagdisenyo ng kurikulum, kasalukuyan laman ng kurikulum na hinango sa Kagawaran ng Edukasyon. Nakabatay rin ang isinagawang pananaliksik sa kasalukuyang lagay at implementasyon ng Filipino sa antas Senior High School.

\section{Resulta}

Narito ang mga panukalang asignaturang sa Filipino para sa senior high school sa iba't ibang track at strand bilang core:

\subsection{Wikang Filipino sa Panahon ng Globalisasyon (Grade 11 - Unang Semestre)}

Bibigyan ang mga mag-aaral sa asignaturang ito ng pag-unawa sa kasaysayan ng wikang Filipino at sa gampanin nito sa lipunan, sa bansa, at sa buong mundo. Ito rin ay lilinang sa kasanayan sa pagbasa at pagsulat sa konteksto ng globalisasyon. Pokus nito ang pagbasa at pagsulat dahil sa mataas na uri ng mga kasanayang nililinang dito.

\subsection{Pagsasaling-wika sa Iba’t ibang Larangan (Grade 11 - Ikalawang Semestre)}

Sa isang bansang multilinggwal at bukas sa daigdig, iba't ibang tao ang nakakasalamuha, iba't ibang wika ang ginagamit. Dahil dito, kinakailangan ng mga mag-aaral ang batayang kaalaman at kasanayan sa pagsasalin lalo sa iba’t ibang sulatin at iba't ibang larangan.

\subsection{Pagpapahalaga sa Rehiyonal at Pambansang Panitikan (Grade 12 - Unang Semestre)}

Ang Pilipinas ay multikultural na bansa. Ito ay binubuo ng iba't ibang pangkat etniko na bumubuo sa pambansang pagkakakilanlan. Ang wika ay kabuhol ng kultura. Ang kultura ang nagbibigay ng kaluluwa sa isang lipunan o komunidad. Ito ang sumisimbolo sa kanilang kalinangan. Bukod sa pagkakaroon ng kaalam sa lokal na panitikan bilang bahagi ng kultura, naaayon din maikintal sa mga mag-aaral ang pagpapahalaga sa mga ito. Layunin ng asignaturang ito manatiling buhay sa mga mag-aaral ang iba't ibang likhang pampanitikan ng Pilipinas.

\subsection{Malikhaing Pagsulat sa Kulturang Pilipino (Grade 12 - Ikalawang Semestre)}

Kasabay ng paglinang ng kritikal o mapanuring pag-iisip ng mga mag-aaral ay ang malikhain pag-iisip nila. Sa paglalayong manatiling buhay at mayaman ang kultura at panitikang Pilipino, bibigyang pagkakataon ang

78 Consortia Academia Publishing (A partner of Network of Professional Researchers and Educators) 
Panukalang kurikulum sa Filipino sa senior high school

mga mag-aaral sa asignaturang ito na magpahayag sa malikhain paraan ukol sa kulturang Pilipino. Nakapokus ang ito sa malikhaing pagsulat ng mga akdang piksyon at di-piksyon.

\section{$\mathrm{K}$ to 12 BASIC EDUCATION CURRICULUM SENIOR HIGH SCHOOL - CORE SUBJECT}

Titulo ng Kurso: Wikang Filipino sa Panahon ng Globalisasyon.

Diskripsyon ng Kurso: Pagkilala sa konteksto ng wika na lilinang sa kasanayang pagbasa at pagsulat tungo sa pagiging mapanuri at kawastuhang aspekto nito na maaring magamit sa pakikipag-ugnayan sa lipunan.

Pamatayang Pangnilalaman: Nauunawaan ang mga konseptong may kinalaman sa proseso, kasaysayan, at kasulukuyang sitwasyon ng wikang Filipino.

Pamantayan sa Pagganap: Nakabubuo ng mga sulatin na maiuugnay ang mga natutuhan sa kapakinabangan ng edukasyon, lipunan at bansang kinabibilangan sa pagtataguyod ng istandardisado at intelektwalisadong wika.

Bilang ng Sesyon: 40 sesyon bawat markahan/ apat na araw sa loob ng isang lingo.

\begin{tabular}{|c|c|c|c|}
\hline NILALAMAN & $\begin{array}{c}\text { PAMANTAYANG } \\
\text { PANGNILALAMAN }\end{array}$ & $\begin{array}{c}\text { PAMANTAYAN SA } \\
\text { PAGGANAP }\end{array}$ & $\begin{array}{c}\text { MGA KASANAYANG } \\
\text { PAMPAGKATUTO }\end{array}$ \\
\hline $\begin{array}{l}\text { Wika } \\
\text { Kalikasan, kahulugan, } \\
\text { katangian, at layunin } \\
\text { Wika bilang instrumento ng } \\
\text { komunikasyon } \\
\text { Makrong Kasanayan sa } \\
\text { Pagbasa } \\
\text { Makrong Kasanayan sa } \\
\text { Pagsulat }\end{array}$ & $\begin{array}{l}\text { Nauunawaan ang kaligirang } \\
\text { pangkasaysayan ng wika, proseso } \\
\text { at ang gampanin nito sa } \\
\text { kasulukuyang panahon }\end{array}$ & $\begin{array}{l}\text { Nabibigyang-halaga ang mga } \\
\text { sitwasyong panlipunan na may } \\
\text { kaugnayan sa wika sa } \\
\text { pamamagitan ng pagsusuri at } \\
\text { paggawa ng mga sulating may } \\
\text { kinalaman sa sariling } \\
\text { komunidad }\end{array}$ & $\begin{array}{l}\text { Naipaliliwanag ang mga } \\
\text { konsepto, katangian at layunin ng } \\
\text { wika tungo sa mabisang } \\
\text { komunikasyon } \\
\text { Naiisa-isa ang mga teorya, } \\
\text { estratehiya at proseso ng pagbasa } \\
\text { at pagsulat }\end{array}$ \\
\hline $\begin{array}{l}\text { Kaligirang Pangkasaysayan ng } \\
\text { Wikang Pambansa } \\
\text { Katutubong Panahon } \\
\text { Panahon ng mga Kastila } \\
\text { Panahon ng mga Amerikano } \\
\text { Panahon ng mga Hapones } \\
\text { Panahon ng Rebolusyunaryo }\end{array}$ & & & $\begin{array}{l}\text { Nakasusunod sa mga estilo ng } \\
\text { pagbasa at pagsulat } \\
\text { Nalalaman ang mga } \\
\text { makabuluhang kaganapan sa } \\
\text { bawat panahon at pag-usbong ng } \\
\text { wikang Filipino }\end{array}$ \\
\hline $\begin{array}{l}\text { Sitwasyon ng Wikang Filipino } \\
\text { sa Modernong Panahon } \\
\text { Pambansa } \\
\text { Global na Ugnayan }\end{array}$ & & & $\begin{array}{l}\text { Naiuugnay ang sitwasyon ng } \\
\text { wikang Filipino sa iba't ibang } \\
\text { bansa } \\
\text { Nakasusulat ng sanaysay na may } \\
\text { kinalamang ang bawat panahon } \\
\text { sa pag-usbong ng wikang } \\
\text { pambansa } \\
\text { Nakagagawa ng mga hakbang sa } \\
\text { pagpapairal ng wikang Filipino sa } \\
\text { mas mataas na diskuro na } \\
\text { maaaring sa pamamagitan ng } \\
\text { talumpati, presentasyon o } \\
\text { pagsasaliksik sa iba't ibang } \\
\text { isyung lokal at nasyonal }\end{array}$ \\
\hline Pinal na Awtput & & $\begin{array}{l}\text { Pagbasa ng mga pananaliksik, } \\
\text { artikulo, pahayagan at pagbuo } \\
\text { ng pamanahong papel na may } \\
\text { kaugnayan sa Wikang Filipino } \\
\text { sa: } \\
\text { Edukasyon } \\
\text { Komunidad } \\
\text { Isyung Panlipunan sa loob at } \\
\text { labas ng bansa }\end{array}$ & $\begin{array}{l}\text { Nakagagawa ng pamanahong } \\
\text { papel ukol sa wikang Filipino na } \\
\text { maaaring may kaugnayan sa } \\
\text { sitwasyon ng edukasyon, } \\
\text { komunidad o mga isyu sa loob at } \\
\text { labas ng bansa }\end{array}$ \\
\hline
\end{tabular}

\section{K to 12 BASIC EDUCATION CURRICULUM \\ SENIOR HIGH SCHOOL - CORE SUBJECT}

Titulo ng Kurso: Pagsasaling-wika sa Iba't Ibang Larangan.

Diskripsyon ng Kurso: Pagtukoy sa mga konseptong may kinalaman sa kurso na lilinang sa kasanayan sa pagsasalin at magamit sa mas mataas na diskurso. 
Punsalan, M. C., Mariano, L. M. P., \& Rosilla, M. B.

Pamatayang Pangnilalaman: Nauunawaan ang kaligiran, layunin at kabuluhan ng pagsasalin sa sariling disiplina tungo sa pagpapaunlad ng kaisipan sa mas mapanuri at mabisang pamamaraan.

Pamantayan sa Pagganap: Nakagagawa ng mga saling-teksto na may kinalaman sa napiling larang tungo sa patuloy na pag-intelektwalisa sa wikang Filipino.

Bilang ng Sesyon: 40 sesyon bawat markahan/ apat na araw sa loob ng isang linggo.

\begin{tabular}{|c|c|c|c|}
\hline NILALAMAN & $\begin{array}{c}\text { PAMANTAYANG } \\
\text { PANGNILALAMAN }\end{array}$ & $\begin{array}{c}\text { PAMANTAYAN SA } \\
\text { PAGGANAP }\end{array}$ & $\begin{array}{c}\text { MGA KASANAYANG } \\
\text { PAMPAGKATUTO }\end{array}$ \\
\hline $\begin{array}{l}\text { Pagsasaling-wika } \\
\text { Konsepto, kahulugan at } \\
\text { kabuluhan } \\
\text { Teorya at Teorista ng Pagsasalin } \\
\text { Mga simulain sa pagsasalin } \\
\text { Patnubay at gampanin sa } \\
\text { kasalukuyang panahon } \\
\text { Mga Etika sa Pagsasaling-wika } \\
\text { Pagsasalin sa Iba't ibang Larang } \\
\text { Propesyon } \\
\text { Literatura } \\
\text { Midya }\end{array}$ & $\begin{array}{l}\text { Nalalaman ang kabuluhan ng mga } \\
\text { konsepto ukol sa } \\
\text { pagsasaling-wika at mga dapat } \\
\text { isaalang-alang sa pagsasagawa } \\
\text { nito }\end{array}$ & $\begin{array}{l}\text { Nagagamit ang mga simulain } \\
\text { sa pagsasaling wika sa } \\
\text { pamamagitan ng: } \\
\text { Pagsusuri sa mga } \\
\text { saling-artikulo, aklat at } \\
\text { pahayagan } \\
\text { Dubbing sa telebisyon, radyo } \\
\text { o iba pang midya } \\
\text { Makapagsalin ng maikling } \\
\text { teksto }\end{array}$ &  \\
\hline Pinal na Awtput & & $\begin{array}{l}\text { Paglalathala ng mga sariling } \\
\text { saling artikulo o iba't ibang } \\
\text { sulatin }\end{array}$ & $\begin{array}{l}\text { Nailalathala ang alinman sa mga } \\
\text { sinaling artikulo o iba't ibang } \\
\text { sulatin sa pagtataguyod ng } \\
\text { istandardisado at } \\
\text { intelektwalisadong wika }\end{array}$ \\
\hline
\end{tabular}

\section{K to 12 BASIC EDUCATION CURRICULUM SENIOR HIGH SCHOOL - CORE SUBJECT}

Titulo ng Kurso: Pagpapahalaga sa Rehiyunal at Pambansang Panitikan.

Deskripsyon ng Kurso: Pag-aaral at kritikal na pagsusuri sa lokal na panitikan ng sariling rehiyon at mabisang pag-unawa sa iba't ibang panitikan ng Pilipinas na sumasaklaw sa iba't ibang elemento, estruktura, konteksto, at tradisyon.

Pamantayang Pangnilalaman: Nasusuri ang iba't ibang lokal na panitikan ng sariling rehiyon maging ang panitikan ng Pilipinas ayon sa kaugnayan nito sa sarili, pamilya, komunidad, bansa at daigdig.

Pamantayan sa Pagganap: Nakasusulat ng isang komprehensibong panunuring pampanitikan hinggil sa lokal na panitikan ng rehiyon at naibabahagi ito sa iba sa tulong ng modernong teknolohiya.

Bilang ng Sesyon: 40 sesyon bawat markahan/apat na araw sa loob ng isang lingo.

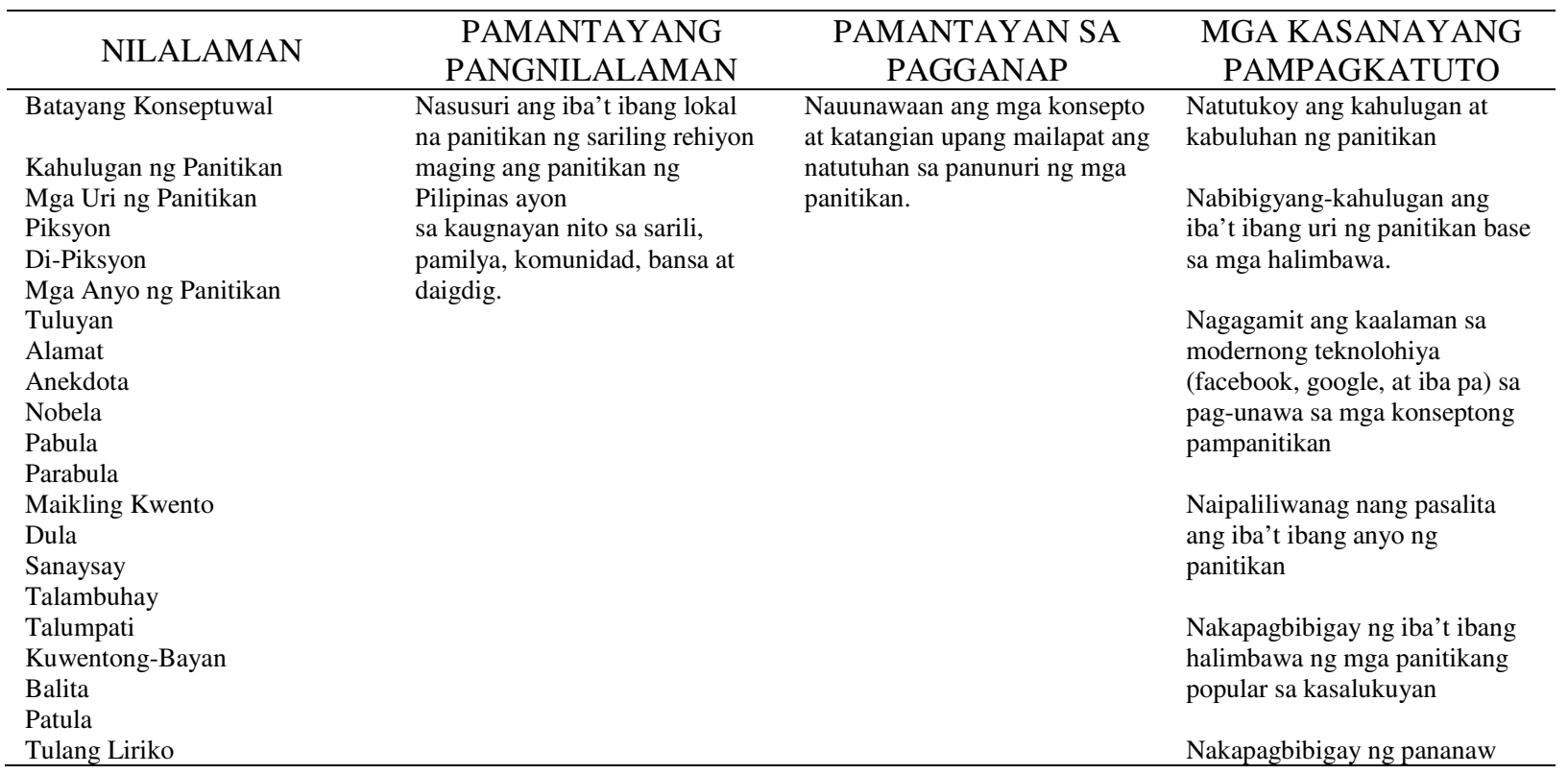

80 Consortia Academia Publishing (A partner of Network of Professional Researchers and Educators) 
Panukalang kurikulum sa Filipino sa senior high school

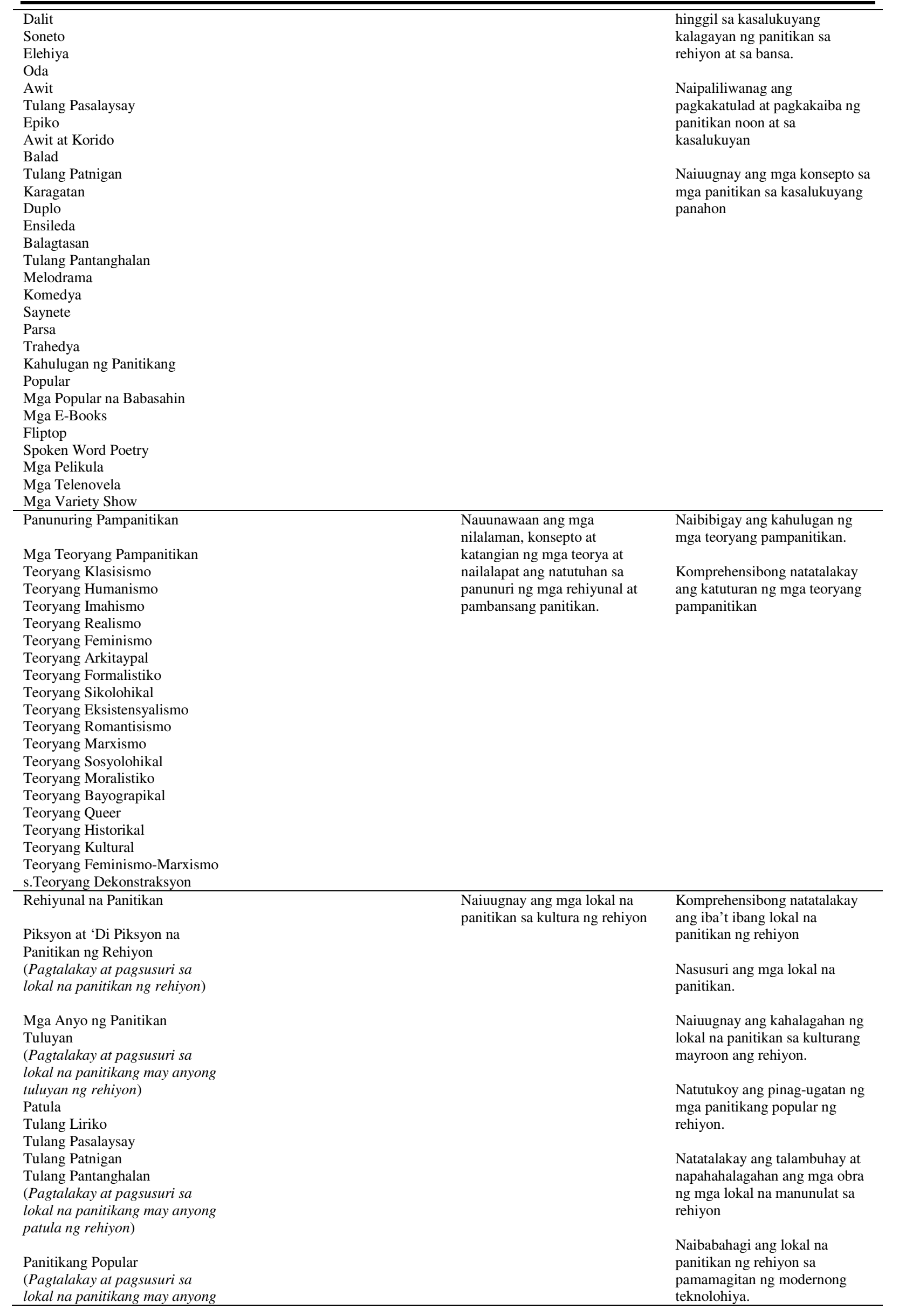


Punsalan, M. C., Mariano, L. M. P., \& Rosilla, M. B.



\section{K to 12 BASIC EDUCATION CURRICULUM SENIOR HIGH SCHOOL - CORE SUBJECT}

Titulo ng Kurso: Malikhaing Pagsulat sa Kulturang Pilipino.

Deskripsyon ng Kurso: Paglinang ng praktikal at malikhaing kasanayan ng mga mag-aaral sa pagbasa at pagsulat sa pamamagitan ng pag-aaral ng mga batayang kaalaman sa pagsulat ng piksyon, patula at pantanghalan. 
Panukalang kurikulum sa Filipino sa senior high school

Pamantayang Pangnilalaman: Natatalakay ang batayang konseptuwal sa malikhaing pagsulat at ang mga pamamaraan sa pagsulat ng isang epektibong sulating napatutungkol sa kulturang Pilipino.

Pamantayan sa Pagganap: Nakasusulat ng isang malikhaing sulatin na nakaangkla sa kulturang Pilipino at naibabahagi ito sa iba sa tulong ng modernong teknolohiya.

Bilang ng Sesyon: 40 sesyon bawat markahan/apat na araw sa loob ng isang lingo.

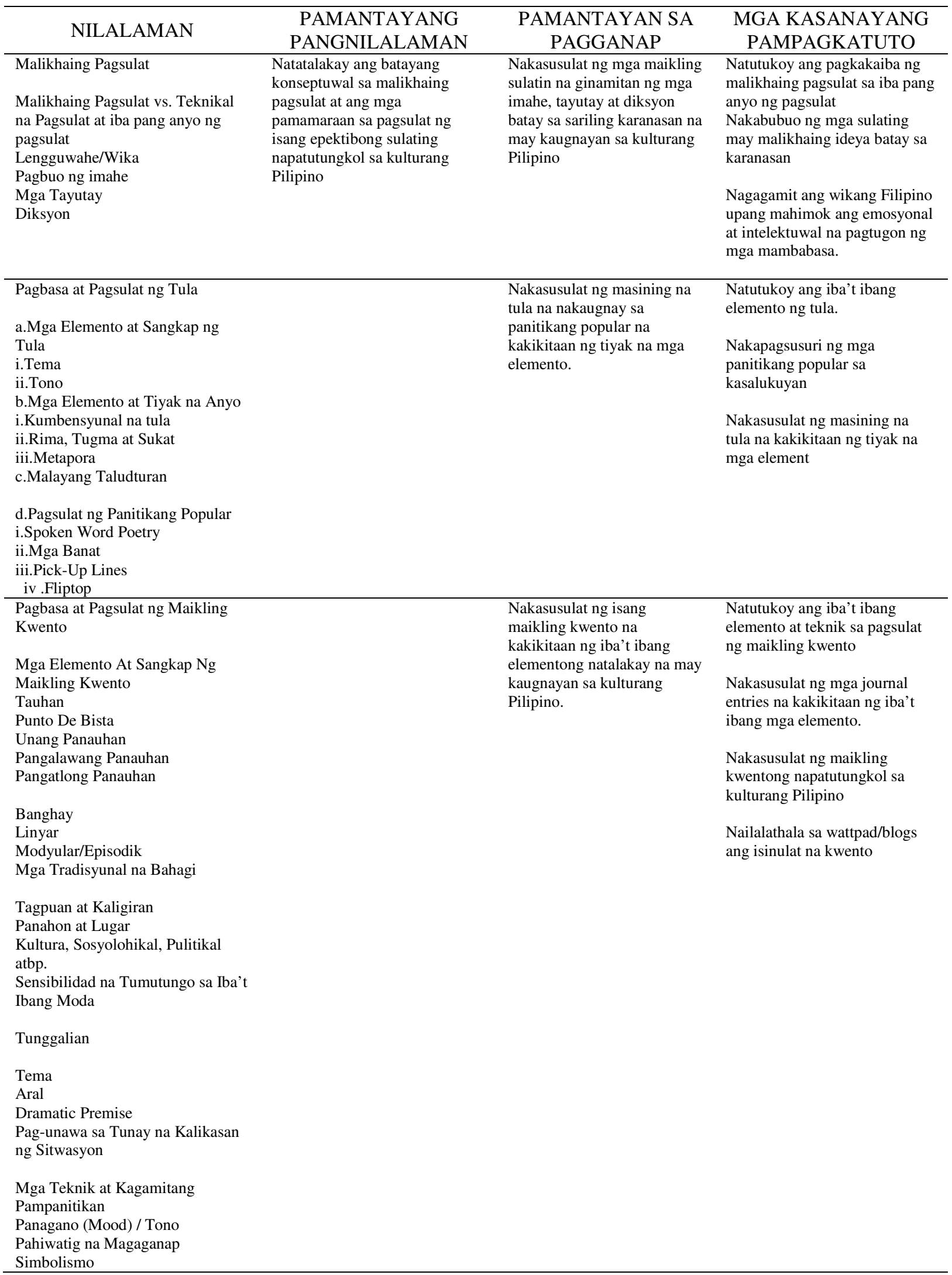




\section{Pagtalakay}

Ang edukasyon sa ika-21 siglo ang umiinog sa konsepto ng globalisasyon. Gayunpaman, hindi dapat kalimutan ang lokal at kultural na ugat ng mga mag-aaral. Maisasakatuparan ito sa pamamagitan ng pag-aaral ng wika at panitikan. Ang wika ay salamin ng kultura. Ang panitikan ay malikhaing pamamaraan upang maipasyag ang tradisyon, paniniwala, gawi, at kultura sa kabuuan ng isang komunidad. Sa paglinang ng mga kasanayang pangwika ng mga mag-aaral sa iba't ibang lente ng kasalukuyang panahon at lipunan, nilalayong matamo ng mga mag-aaral ang kaisipang global at maimulat sila sa tunay na kalagayan ng mundo nang hindi nagpag-iiwanan ang paggamit ng wikang pambansa na ang malaking papel ay bilang isang wikang intelektwalisado.

Ang panitikan ay siyang magpapatibay ng pagpapanatili ng mga kaalamang-bayan, pagpapahalaga sa sariling identidad bilang bahagi ng isang kultural na komunidad, at pagkakaroon ng dibersidad sa lipunan. Sa halip na magkawatak-watak at magkaroon ng dibisyon ang bawat etnolinggwistiskong pangkat sa bansa, ang pagtuturo ng lokal na panitikan ay ambag sa lalong pagpapayaman ng pambansang identidad at kaalaman.

Ang mga panukalang asignaturang ito ay nagnanais na malinang ang analitiko, kritikal, kolaboratibo, komunikatibo, malikhaing pag-iisip ng mga mag-aaral.

\section{Kongklusyon}

Sa pagsasagawa ng kurikulum, mahalagang isaalang-alang ang mga layunin na nais matamo sa kabuuan ng pag-aaral. Mga mag-aaral na pangunahing salik sa pagbuo ng kurikulum at higit sa lahat, kinakailangang bigyang-diin ang hinihingi sa kasalukuyang panahon na nakaangkla sa pangangailangan ng mga mag-aaral na kung saan ay hindi lamang nakabatay sa dikta ng nasa taas o kagustuhan ng mga ito.

Ipinipakita sa binuong kurikulum na hindi lamang nakatuon sa kung paano ang pagkatuto ng wika o pag-alam sa mga kasanayang maaaring mahubog ng mag-aaral sa pag-unawa sa mga paksang inilahad bagkus, tiningnan din ng mga bumuo nito na mahalagang iugnay sa kabuuang aspekto na mag-aaral upang mapaghusay at malinang ang mga kasanayan.

Tinalakay sa nasabing kurikulum, ang mga konsepto ukol sa wika kung paano ang pagkakabuo, pag-usbong ng wikang pambansa at kaligirang pangkasaysayan nito. Gayundin, ang pagsasaling-wika, sapagkat ang kaisipang namutawi sa mga bumuo ng kurikulum na mahalagang matutuhan ng mga mag-aaral ang konteksto nito upang magamit sa napiling larang o disiplina. Maliban pa rito ay tinalakay din ang mga panitikang panrehiyon at pambansa na kung titingnan, idinagdag ito upang mas lalo pang mapahalagahan ang panitikang kinamulatan ng bawat pangkat at magamit ito sa diskurso ng edukasyon. Inilahad din sa papel na ito ang pagtatasa sa mga makrong kasanayan na pangunahing tunguhin ng programa ng K-12 sa pagtatamo ng kaalaman tungo sa pagiging istandardisado at intelektwalisadong wika. 


\subsection{Rekomendasyon}

Inirerekomenda ang mga sumusunod:

$>\quad$ Sipating muli ang mga asignaturang Filipino na kasalukuyang ipinatutupad ng Kagawaran ng Edukasyon sa aspeto ng kahalagahang akademiko at kultural sa mga mag-aaral;

$>\quad$ Magkaroon ng pilot testing sa mga panukalang asignatura at tayain ang perspesepyon ng mga mag-aaral, guro, administrador, magulang, at iba pang stakeholders ukol dito;

$>\quad$ Ilapit ang tunay na danas ng lipunan sa mga akdemikong gawain upang maihanda ang mga mag-aaral sa kahaharapin sa labas ng paaralan; at

$>\quad$ Panatilihing nakasandig sa kultura ang edukasyon upang manatiling buhay at metatag ang bawat wika at kultura sa bansa.

\section{Mga sanggunian}

Batnag, A. (n. d.). Translation in the Philippines. Retrieved from NCCA:

http://gwhs-stg02.i.gov.ph/ s2nccagovph/subcommissions/subcommission-on-cultural-disseminationsc d/language-and-translation/translation-in-the-philippines/?fbclid=IwAR0QBH3Iy4ahjpbzaq9r7nNAY4 NTIUqzRxRqEkxgdUPwrzoppHcJQ8Yo9W4

Bio, D. B. (2011, January). BICS/CALP: Basic interpersonal communicative skills vs. cognitive academic language proficiency. Retrieved from Best of Bilash: Improving Second Language Education: https://sites.educ.ualberta.ca/staff/olenka.bilash/Best\%20of\%20Bilash/bics\%20calp.html?fbclid=IwAR 2j0X-vfQ-6t52GAWkHkcwYOUxURDadOvpOUWHsrDc_u-joRBzGkpvOOMQ

Catacataca, P. (n. d.). The use of Filipino in official transactions, communication and correspondence. Retrieved from NCCA:

http://gwhs-stg02.i.gov.ph/ s2nccagovph/subcommissions/subcommission-on-cultural-disseminationsc d/language-and-translation/the-use-of-filipino-in-official-transactions-communication-and-corresponde nce/?fbclid=IwAR0c3Ou2XZvZdbKx0tGy2llVUhoR8EPXphHtmiQyNseY

Deped. (n. d.). Retrieved from

http://www.deped.gov.ph/wp-content/uploads/2019/01/SHS-Core_Komunikasyon-at-Pananaliksik-sa-W ika-at-Kulturang-Pilipino-CG.pdf?fbclid=IwAR251PGoYRxbs2W4oVgms0dNFpsCVClgVbx6XviZitb Bll6zYn4R_1YOwm0

Espiritu, C. (n. d.). Filipino language in the curriculum. Retrieved from NCCA.

http://gwhs-stg02.i.gov.ph/ s2nccagovph/subcommissions/subcommission-on-cultural-disseminationsc d/language-and-translation/filipino-language-in-the-curriculum/?fbclid=IwAR251PGoYRxbs2W4oVg ms0dNFpsCVClgVbx6XviZitbB1l6zYn4R_1YOwm0

Miclar, M. (n. d.). Ang kalagayan ng Filipino sa panahon ngayon. Retrieved from NCCA. http://gwhs-stg02.i.gov.ph/ s2nccagovph/subcommissions/subcommission-on-cultural-disseminationsc d/language-and-translation/ang-kalagayan-ng-filipino-sa-panahon-ngayon/?fbclid=IwAR0oZpQaNRcJ mK4kRciyRDr3CNZmjemp1lij2kecRWjuJ8Q8fGmeuURyMjY

Ocampo, J. (2016). Pagtuturo ng Filipino mula senior high, binigyang-diin ng tomasinong guro. Retrieved from The Varsitarian.

https://varsitarian.net/news/20160929/pagtuturo-ng-filipino-mula-senior-high-binigyang-diin-ng-tomasi nong-guro?fbclid=IwAR3m-DcJbYKS6_nZLQzrjxjfBDiVIJmoco-M19ptL1ammlVC5wNqT9txlz4

Quijano, C. (2012). The role of language and education in globalization. Philippines. 
Punsalan, M. C., Mariano, L. M. P., \& Rosilla, M. B.

86 Consortia Academia Publishing (A partner of Network of Professional Researchers and Educators) 